\title{
The Geometrical Effect on the Von Mises Stress on Ball and Socket Artificial Discs
}

\author{
Feras Adnan Alnaimat \\ Medical Engineering Department \\ Faculty of Engineering \\ Al-Ahliyya Amman University \\ Al-Saro, Al-Salt, Amman, Jordan \\ f.alnaimat@ammanu.edu.jo
}

\begin{abstract}
Wear has been considered as a major issue for ball and socket artificial discs. This paper studies the effects of ball radius and radial clearance of the artificial disc on the von Mises stresses. Different material combinations, used in artificial discs, are compared. FEA simulation using Solidworks has been conducted for different disk geometries. The highest von Mises stress was $714 \mathrm{MPa}$ for $10 \mathrm{~mm}$ radius metal against metal design. The lowest von Mises stress was $14.8 \mathrm{MPa}$ for $16 \mathrm{~mm}$ radius of the UHMWPE/CoCr material combination, which exhibited the lowest von Mises stresses for all the radii of the ball and socket articulation. Considering radial clearance, the lowest von Mises stress was $14.8 \mathrm{MPa}$ for $0.015 \mathrm{~mm}$ clearance of the UHMWPE/CoCr combination. The highest von Mises stress of $100.8 \mathrm{MPa}$ with a radial clearance of $0.25 \mathrm{~mm}$ was recorded for the same combination. There is a strong relation between the von Mises stress and the geometry of the ball and socket of the artificial disc.
\end{abstract}

Keywords-FEA; von Mises stress; radial clearance; artificial disc; artificial joint

\section{INTRODUCTION}

Intervertebral discs are majorly responsible for back motions [1]. There are 24 discs in the spine which have the same shape but different sizes [2]. Intervertebral discs lose their mechanical ability of holding compression loads and giving the required motion without causing pain when they get degenerated [3]. Artificial discs have been introduced to relieve disc pain and to restore the required mechanical motion [4]. Ball and socket articulation idea came from artificial hips and has been widely used to design artificial discs [5]. One of the major problems articulation joints face is the wear particles resulting from the friction between the ball and socket artificial joints [6-8]. These wear particles migrate to the surrounding tissues causing inflammation response and toxicity [9]. Researchers have been trying to use different material combinations such as metal against metal, metal against polymers and ceramic against ceramic to solve this problem $[10]$. Others tried to understand the link between the geometry of the ball and socket and the lubrication regime [11-15]. One of the main effects of increasing the radius of the ball is that it is increasing the range of motion for the implant for flexion, extension and lateral bending. In addition, the force facing the facet joint was lower with the larger radius of the ball for all motions [16]. Other studies showed that increasing the radius of the ball has a direct effect on the lubricant film thickness enhancing the lubrication regime of the implant [17]. It has been noticed that the film thickness decreases with increasing radial clearance of the ball and socket artificial joint $[15,17]$. Choosing the right geometry of the ball and socket could improve the artificial joints lubrication regime and reduce the wear and friction generated from the articulation between them [18]. There is a direct relationship between the wear and the contact stress. It was found that the wear increases with higher contact stress [19]. There is a direct relationship between the von Mises and contact stresses as the contact stress increases when the von Mises stress increases [20]. Maximum distortion energy was obtained by studying the strain energy that develops at a material point [21].

In this study, different geometries with different materials and the stresses these designs face are studied with the use of simulation software. BS ISO 21534:2009 [22] suggests that different material combinations could be used in joint replacement. The aim of this study is to compare the different geometrical designs of the ball and socket artificial discs on von Mises stresses and to study the effect of the different material combinations on the stresses these geometrical designs face.

\section{METHODOLOGY AND MATERIALS}

\section{A. Methods}

Different artificial disc geometrical designs have been simulated using Solidworks (Dassault Systèmes SolidWorks Corp., Massachusetts, USA). The focus of changing the geometry was to use different radii for the balls and sockets. Seven radii for the ball and socket were chosen with radial clearance of $0.015 \mathrm{~mm}$. This radial clearance has been chosen after comparing different radial clearances with SolidWorks simulation tool. Some of these ball and socket radii were similar to the design geometries used in the market. Each design consisted of a socket and a ball. The ball part was designed with different radii, such as $10,11,12,13,14,15$ and $16 \mathrm{~mm}$. Different ball radii in the $5-20 \mathrm{~mm}$ range have been simulated in [23]. The socket part was designed with the same geometry of the ball but adding to each radius a radial clearance of $0.15 \mathrm{~mm}$. A static solid model using Solidworks 
with tetrahedral solid elements was used to simulate the finite element analysis of the models with different geometries. The total number of nodes for the different geometries varied between 74913 and 78765 . Figure 1 shows the ball part design before assembly and simulation. An axial force of $2000 \mathrm{~N}$ was applied on the upper plate of the socket. It is the maximum force that can be applied according to the standard ISO 181921:2011 [24]. The ball and socket artificial disc was fixed from the bottom plate of the ball as the loads come axially from above [24], as shown in Figure 4. Figure 2 shows the fine mesh of the ball and socket artificial disc with 78765 tetrahedral solid elements used in the simulation.

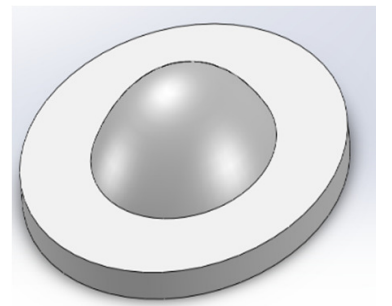

(a)

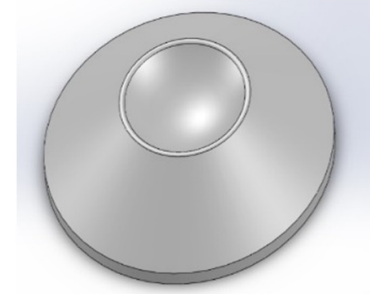

(b)

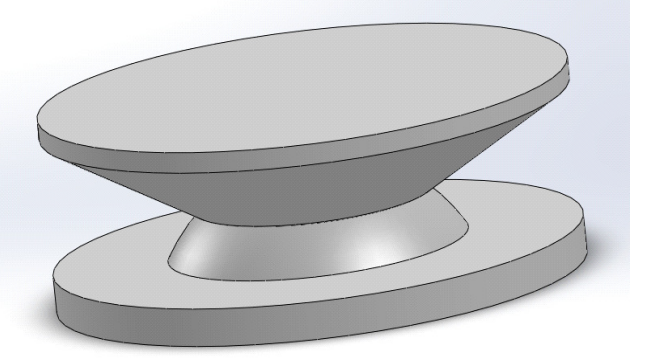

(c)

Fig. 1. (a) Ball part and (b) socket part of the artificial disc. (c) The artificial disc assembly.

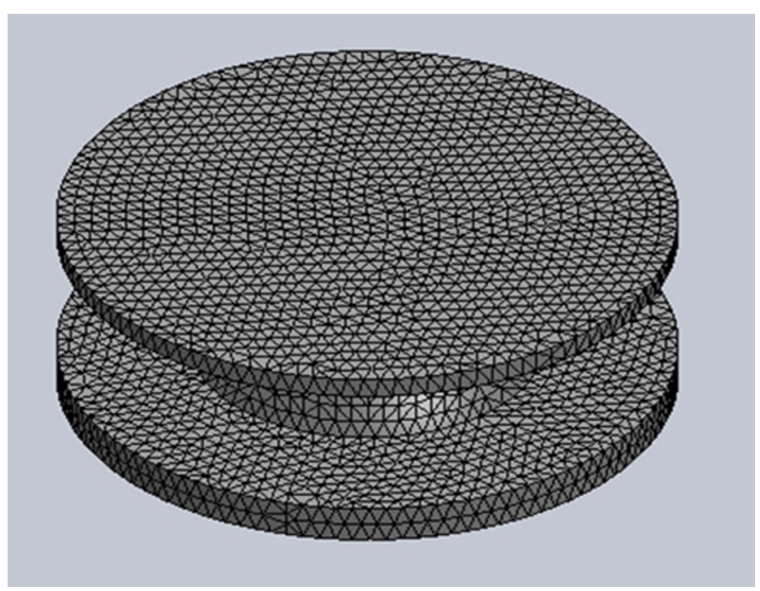

Fig. 2. Mesh of the ball and socket artificial disc assembly.

\section{B. Materials}

Cobalt-28 chromium- 6 molybdenum ( $\mathrm{CoCr}$ ) alloy castings that are used in implants were used in this simulation. The $\mathrm{CoCr}$ against $\mathrm{CoCr}$ has been used in Maverick and Kinefelx artificial discs $[25,26]$. UHMWPE was used as the socket part of the artificial disc implant. The UHMWPE against $\mathrm{CoCr}$ combination have been used in multiple artificial discs such as Charite and Prodisc artificial discs [27, 28]. Polyether Ether Ketone (PEEK) against PEEK combination has been used to produce $\mathrm{NuNec}$ artificial discs [29, 30]. Metal against metal materials were designed and simulated using a $\mathrm{CoCr}$ socket against a CoCr ball. Other models were designed and simulated using polymer against metal materials and UHMWPE socket against $\mathrm{CoCr}$ ball. Polymer against polymer materials were designed and simulated using PEEK socket against PEEK ball. The materials' mechanical properties are listed in Table I.

TABLE I. MATERIALS MECHANICAL PROPERTIES [31-33]

\begin{tabular}{|c|c|c|c|}
\hline Mechanical properties & $\mathbf{C o C r}$ & UHMWPE & PEEK \\
\hline Yield strength (Pa) & $4.5 \times 10^{8}$ & $2.3 \times 10^{7}$ & $9.3 \times 10^{7}$ \\
\hline Tensile strength (Pa) & $2.35 \times 10^{8}$ & $5.3 \times 10^{7}$ & $1.1 \times 10^{8}$ \\
\hline Elastic modulus (Pa) & $2.11 \times 10^{11}$ & $7.25 \times 10^{8}$ & $4 \times 10^{9}$ \\
\hline Poisson's ratio (Pa) & 0.31 & 0.46 & 0.36 \\
\hline Mass density (Kg/m3) & 8900 & 930 & 1300 \\
\hline Shear modulus (Pa) & $8.8 \times 10^{10}$ & $3.2 \times 10^{8}$ & $1.425 \times 10^{9}$ \\
\hline
\end{tabular}

\section{RESULTS AND DISCUSSION}

\section{A. Results}

The results of the FEA simulation showed that, as expected, the ball and socket had the highest von Mises stress on the edges of the socket (Figure 3). The highest von Mises stress was $14.8 \mathrm{MPa}$ on the edges of the UHMWPE socket and the lowest stress was $0.04 \mathrm{MPa}$ for the same combination. The design with the $16 \mathrm{~mm}$ radius of the ball and socket showed a von Mises stress lower than the yield stress of the UHMWPE used in the simulation of the artificial disc. The von Mises stress gradually reduced by moving away from the edges of the socket and increased again when reaching the lowest point of the concave part of the socket reaching around $11 \mathrm{MPa}$, as shown in Figure 3.

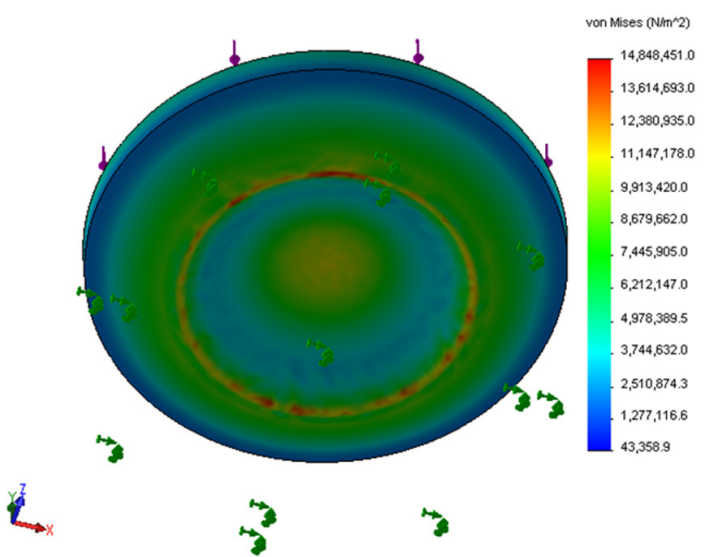

Fig. 3. The von Mises stress of the UHMWPE socket with $16.015 \mathrm{~mm}$ radius after FEA simulation.

Figure 4 shows the FEA simulation of the ball and socket artificial disc assembly. The UHMWPE socket faces most of the high stresses. The highest stresses on the ball part were 
caused by the edges of the socket in direct contact, where the von Mises stresses were between $5 \mathrm{MPa}$ and $10 \mathrm{MPa}$.

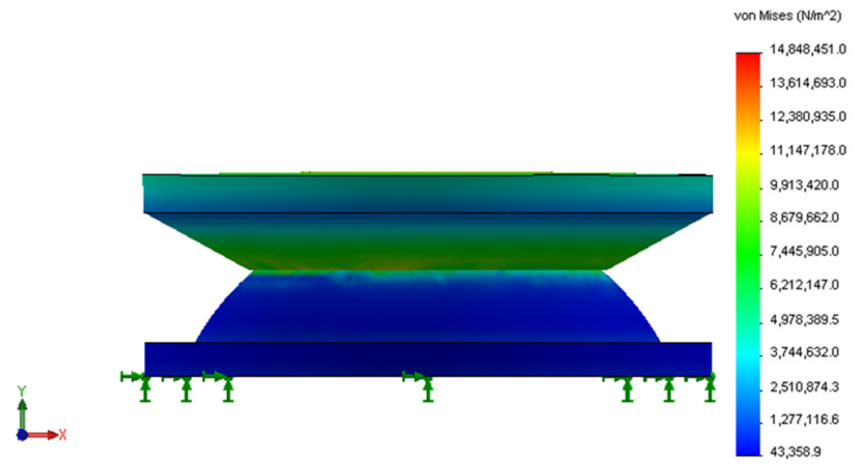

Fig. 4. FEA simulation of the UHMWPE socket against a $\mathrm{CoCr}$ ball with $16 \mathrm{~mm}$ radius.

The von Mises stresses were different for the $\mathrm{CoCr}$ socket against $\mathrm{CoCr}$ ball in which the socket did not face a lot of stresses on the top edges of the socket like the UHMWPE socket. The stresses were concentrated on the top center of the socket and this could be due to the higher $450 \mathrm{MPa}$ yield strength of the CoCr used in this study.

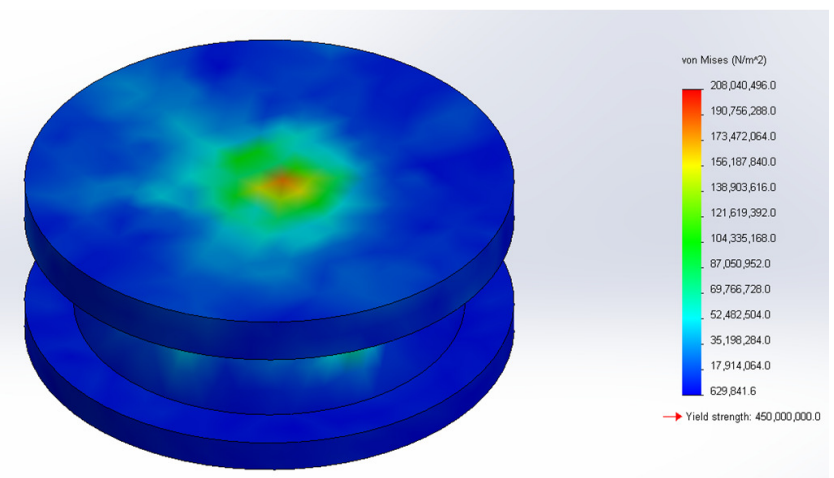

Fig. 5. FEA simulation of the $\mathrm{CoCr}$ socket against a $\mathrm{CoCr}$ ball with $14 \mathrm{~mm}$ radius.

The highest von Mises stress was $714 \mathrm{MPa}$ for the $10 \mathrm{~mm}$ radius ball and the socket metal against metal design. The lowest von Mises stress for the same material combination but with a larger radius of $16 \mathrm{~mm}$ was $153.4 \mathrm{MPa}$, as shown in Figure 6. For the PEEK against PEEK combination, the highest von Mises stress was $682 \mathrm{MPa}$ for the $10 \mathrm{~mm}$ radius and the lowest was $24 \mathrm{MPa}$ for the $16 \mathrm{~mm}$ radius design. The highest von Mises stress for the UHMWPE against $\mathrm{CoCr}$ combination was $44 \mathrm{MPa}$ for the $10 \mathrm{~mm}$ radius and the lowest was $14.8 \mathrm{MPa}$ for the $16 \mathrm{~mm}$ radius. It was noticed that the von Mises stress reduced when the ball and socket radius was increased for all material combinations. The contact stress showed nearly the same trend as the von Mises stress. They both showed a decrease with the increment of the ball radius (Figure 7). Radial clearance is a factor well-known for affecting the lubrication regime in any ball and socket artificial joint. This study showed that the radial clearance had an effect on the von
Mises stress as well, as shown in Figure 8. It was noticed that by increasing the radial clearance, the von Mises increased for the $16 \mathrm{~mm}$ socket to reach about $100 \mathrm{MPa}$ in the UHMWPE against $\mathrm{CoCr}$ combination. The lowest von Mises stress of $14.8 \mathrm{MPa}$ was for a radial clearance of $0.015 \mathrm{~mm}$ for the same combination.

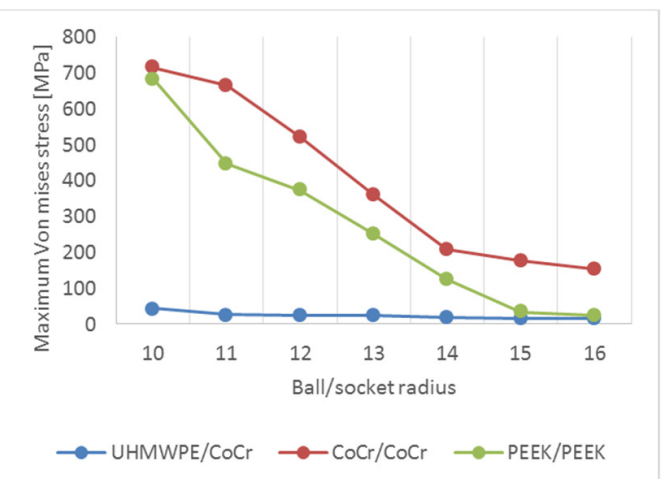

Fig. 6. Von Mises stress of the different geometries and material combinations.

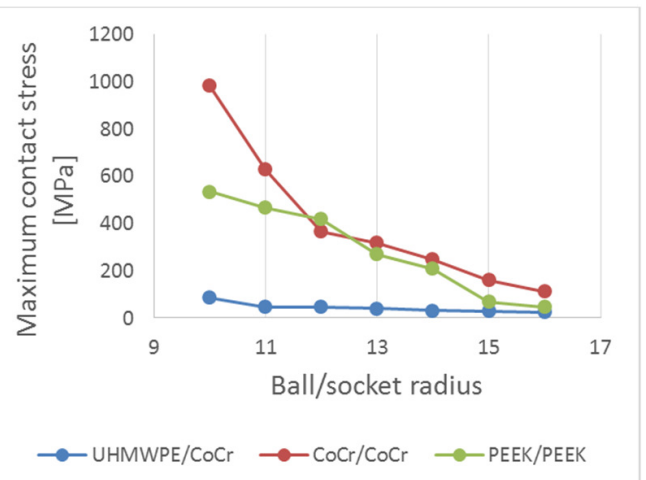

Fig. 7. Contact stress of the different geometries and material combinations.

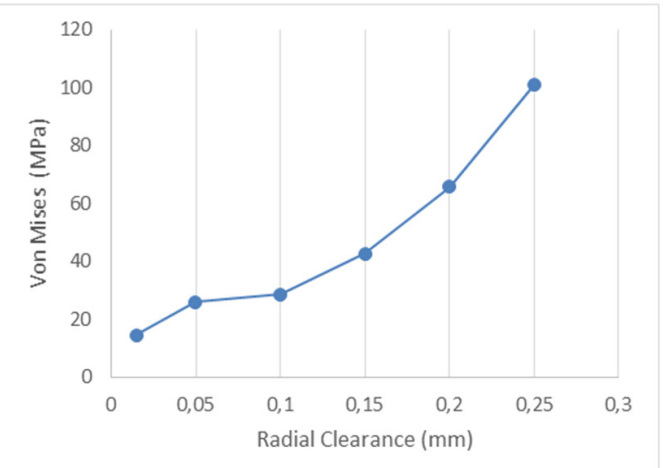

Fig. 8. Radial clearance effect on the von Mises stresses facing the $16 \mathrm{~mm}$ radius socket for the UHMWPE against $\mathrm{CoCr}$ combination.

\section{B. Discussion}

Ball and socket artificial disc simulations showed that the maximum von Mises stress occurred on the edges of the contact between the ball and socket. It is suggested by the 
results that any design for the ball and socket must be curved on the contact edges. The blue area on the concave part of the socket in Figures 3 and 7 was due to the $0.015 \mathrm{~mm}$ radial clearance applied on the design of the socket. The UHMWPE socket showed higher von Mises stresses than the CoCr ball as was expected due to the higher yield modulus of the $\mathrm{CoCr}$ mentioned in Table I. In this kind of articulation, it is most likely that the wear particles will be from the UHMWPE [34]. There is a direct relationship between wear volume, contact stress, and Von Mises stress [19, 20]. This study investigated the way the von Mises stress is applied on artificial joints of different material combinations and the effect of radial clearance on the artificial joint using FEA simulation, instead of mathematical calculations $[11,15]$. These stresses are important to be analyzed and understood in depth as they can affect the facial joints at the treated level by increasing the force these joints face $[35,36]$. The UHMWPE against $\mathrm{CoCr}$ combination had the lowest von Mises stresses for all designs. PEEK against PEEK combination had higher von Mises stresses than UHMWPE against CoCr. The highest von Mises stresses occurred for the $\mathrm{CoCr}$ against $\mathrm{CoCr}$ combination, which was expected [37]. In addition, the highest friction coefficient for the different combinations was for $\mathrm{CoCr}$ against $\mathrm{CoCr}$ and the lowest for UHMWPE against $\mathrm{CoCr}$ [38].

Larger radii of the ball and socket artificial discs showed a lower von Mises stress for all material combinations, as shown in Figure 5. Also, it has been shown that a larger radius of the ball and socket artificial disc will help reduce the resulting wear $[15,39,40]$. In this aspect, there is a sharp contrast with the previous published theoretical results in which the wear and friction increase with the decrease of ball radius [18, 31].

It has been noticed from Figures 3 and 7 that the highest stresses were applied on the edges of the socket. This would cause them to wear more than the rest of the socket. Improving the design to make it curvier would have an impact in reducing the von Mises stress. Maverick is one of the artificial discs which have a design of curved edges of the socket part [25]. The radial clearance had a direct effect on the von Mises stress. Increasing the radial clearance caused increment on the von Mises stress, as shown in Figure 8. The benefit of the radial clearance is that it enhances the lubrication film thickness between the ball and socket. However, it could increase the von Mises stress of the implant. Authors in [15] found that by decreasing the radial clearance of the ball the fluid film thickness will be increased and this will cause a fluid film lubrication regime. Authors in [41] reported similar results stating that there is a direct relation between the radial clearance and the lubrication regime in which decreasing the radial clearance will increase the film thickness of the lubricant.

\section{CONCLUSION}

It has been found that there is a relationship between the von Mises stress and the ball radius of the artificial joints. The UHMWPE against CoCr compilation had the lowest von Mises stress values for all radii. In addition, there is a strong relation between the radial clearance of the socket and the von Mises stresses facing the articulation. The conclusions of this study are:
- Von Mises stress was the highest with 714MPa for the $10 \mathrm{~mm}$ radius ball and socket metal against metal combination.

- The lowest von Mises stress was $14.8 \mathrm{MPa}$ for the $16 \mathrm{~mm}$ radius for the UHMWPE against CoCr combination.

- There is a strong relationship between the von Mises stresses and the radius of the ball and socket artificial discs.

- The von Mises stresses increase with the increment of the radial clearance of the socket part.

- UHMWPE against CoCr combination showed the lowest von Mises stresses for all ball radii.

- $\mathrm{CoCr}$ against $\mathrm{CoCr}$ combination showed the highest von Mises stress for all ball radii.

\section{REFERENCES}

[1] G. D. Cramer and S. A. Darby, Basic and Clinical Anatomy of the Spine, Spinal Cord, and ANS, 2nd Edition. London, UK: Mosby, 2005.

[2] N. Palastanga, D. Field, and R. W. Soames, Anatomy and Human Movement: Structure and Function, 2nd Edition. Oxford, UK: Elsevier, 2013.

[3] H. A. L. Guerin and D. M. Elliott, "Structure and Properties of Soft Tissues in the Spine," in Spine Technology Handbook, S. M. Kurtz and A. A. Edidin, Eds. London, UK: Elsevier Academic Press, 2006, pp. 3562.

[4] S. M. Kurtz, "Total Disc Arthroplasty," in Spine Technology Handbook, A. A. Edidin and S. M. Kurtz, Eds. London, UK: Elsevier Academic Press, 2006, pp. 303-370.

[5] Q. B. Bao and H. A. Yuan, "Artificial disc technology," Neurosurgical Focus, vol. 9, no. 4, Oct. 2000, doi: 10.3171/foc.2000.9.4.14, Art. no. e14.

[6] E. Ingham and J. Fisher, "Biological reactions to wear debris in total joint replacement," Proceedings of the Institution of Mechanical Engineers, Part H: Journal of Engineering in Medicine, vol. 214, no. 1, pp. 21-37, Jan. 2000, doi: 10.1243/0954411001535219.

[7] S. B. Goodman, "Wear particles, periprosthetic osteolysis and the immune system," Biomaterials, vol. 28, no. 34, pp. 5044-5048, Dec. 2007, doi: 10.1016/j.biomaterials.2007.06.035.

[8] Y. Kadoya, A. Kobayashi, and H. Ohashi, "Wear and osteolysis in total joint replacements," Acta Orthopaedica Scandinavica, vol. 69, no. sup278, pp. i-16, Jan. 1998, doi: 10.1080/17453674.1998.11744778.

[9] S. R. Golish and P. A. Anderson, "Bearing surfaces for total disc arthroplasty: metal-on-metal versus metal-on-polyethylene and other biomaterials," The Spine Journal, vol. 12, no. 8, pp. 693-701, Aug. 2012, doi: 10.1016/j.spinee.2011.05.008.

[10] Q.-B. Bao, G. M. Mccullen, P. A. Higham, J. H. Dumbleton, and H. A. Yuan, "The artificial disc: theory, design and materials," Biomaterials, vol. 17, no. 12, pp. 1157-1167, Jun. 1996, doi: 10.1016/01429612(96)84936-2.

[11] A. Shaheen and D. E. T. Shepherd, "Lubrication regimes in lumbar total disc arthroplasty," Proceedings of the Institution of Mechanical Engineers, Part H: Journal of Engineering in Medicine, vol. 221, no. 6, pp. 621-627, Jun. 2007, doi: 10.1243/09544119JEIM204.

[12] P. Moghadas, A. Mahomed, D. W. L. Hukins, and D. E. T. Shepherd, "Friction in metal-on-metal total disc arthroplasty: Effect of ball radius," Journal of Biomechanics, vol. 45, no. 3, pp. 504-509, Feb. 2012, doi: 10.1016/j.jbiomech.2011.11.045.

[13] R. M. Streicher, M. Semlitsch, R. Schon, H. Weber, and C. Rieker, "Metal-On-Metal Articulation for Artificial Hip Joints: Laboratory Study and Clinical Results," Proceedings of the Institution of Mechanical Engineers, Part H: Journal of Engineering in Medicine, vol. 210, no. 3, pp. 223-232, Sep. 1996, doi: 10.1243/PIME_PROC_ 1996_210_416_02. 
[14] R. A. Scott and D. W. Schroeder, "The effect of radial mismatch on the wear of metal on metal hip prosthesis: a hip simulator study," in Transactions of the Annual Meeting of the Orthopaedic Research Society, vol. 22, 1997.

[15] Z. M. Jin, D. Dowson, and J. Fisher, "Analysis of fluid film lubrication in artificial hip joint replacements with surfaces of high elastic modulus," Proceedings of the Institution of Mechanical Engineers, Part H: Journal of Engineering in Medicine, vol. 211, no. 3, pp. 247-256, Mar. 1997, doi: 10.1243/0954411971534359.

[16] J. Choi, D.-A. Shin, and S. Kim, "Biomechanical Effects of the Geometry of Ball-and-Socket Artificial Disc on Lumbar Spine: A Finite Element Study," Spine, vol. 42, no. 6, pp. E332-E339, Mar. 2017, doi: 10.1097/BRS.0000000000001789.

[17] D. Jalali-Vahid, M. Jagatia, Z. M. Jin, and D. Dowson, "Prediction of lubricating film thickness in UHMWPE hip joint replacements," Journal of Biomechanics, vol. 34, no. 2, pp. 261-266, Feb. 2001, doi: 10.1016/ S0021-9290(00)00181-0.

[18] A. Wang, A. Essner, and R. Klein, "Effect of contact stress on friction and wear of ultra-high molecular weight polyethylene in total hip replacement," Proceedings of the Institution of Mechanical Engineers, Part H: Journal of Engineering in Medicine, vol. 215, no. 2, pp. 133139, Feb. 2001, doi: 10.1243/0954411011533698.

[19] A. Ravikiran and S. Jahanmir, "Effect of contact pressure and load on wear of alumina," Wear, vol. 251, no. 1, pp. 980-984, Oct. 2001, doi: 10.1016/S0043-1648(01)00739-6.

[20] Y. Wang, Y. Fan, and M. Zhang, "Comparison of stress on knee cartilage during kneeling and standing using finite element models," Medical Engineering \& Physics, vol. 36, no. 4, pp. 439-447, Apr. 2014, doi: 10.1016/j.medengphy.2014.01.004.

[21] F. A. Leckie and D. J. Bello, Strength and Stiffness of Engineering Systems. New York, NY, USA: Springer, 2009.

[22] ISO/CD 21534: Non-active surgical implants - Joint replacement implants - Particular requirements. ISO, 2007.

[23] A. Rohlmann, A. Mann, T. Zander, and G. Bergmann, "Effect of an artificial disc on lumbar spine biomechanics: a probabilistic finite element study," European Spine Journal, vol. 18, no. 1, pp. 89-97, Jan. 2009, doi: 10.1007/s00586-008-0836-1.

[24] ISO 18192-1:2011: Implants for surgery - Wear of total intervertebral spinal disc prostheses - Part 1: Loading and displacement parameters for wear testing and corresponding environmental conditions for test, 2nd ed. ISO, 2011.

[25] H. H. Mathews, J.-C. LeHuec, T. Friesem, T. Zdeblick, and L. Eisermann, "Design rationale and biomechanics of Maverick Total Disc arthroplasty with early clinical results," The Spine Journal, vol. 4, no. 6, Supplement, pp. S268-S275, Nov. 2004, doi: 10.1016/j.spinee.2004 .07 .017 .

[26] U. R. Hahnle, I. R. Weinberg, K. Sliwa, B. M. Sweet, and M. de Villiers, "Kineflex (Centurion) Lumbar Disc Prosthesis: Insertion Technique and 2-Year Clinical Results in 100 Patients," International Journal of Spine Surgery, vol. 1, no. 1, pp. 28-35, Jan. 2007, doi: 10.1016/SASJ-20060005-RR.

[27] S. Blumenthal et al., "A Prospective, Randomized, Multicenter Food and Drug Administration Investigational Device Exemptions Study of Lumbar Total Disc Replacement With the CHARITÉ ${ }^{\mathrm{TM}}$ Artificial Disc Versus Lumbar Fusion: Part I: Evaluation of Clinical Outcomes," Spine, vol. 30, no. 14, pp. 1565-1575, Jul. 2005, doi: 10.1097/01.brs. 0000170587.32676.0e

[28] R. B. Delamarter, D. M. Fribourg, L. E. A. Kanim, and H. Bae, "ProDisc Artificial Total Lumbar Disc Replacement: Introduction and Early Results From the United States Clinical Trial," Spine, vol. 28, no. 20S, pp. S167-S175, Oct. 2003, doi: 10.1097/01.BRS.0000092220.66650.2B.

[29] H. Xin, D. E. T. Shepherd, and K. D. Dearn, “A tribological assessment of a PEEK based self-mating total cervical disc replacement," Wear, vol. 303, no. 1, pp. 473-479, Jun. 2013, doi: 10.1016/j.wear.2013.03.052.

[30] M. Kraft, D. K. Koch, and M. Bushelow, "An investigation into PEEKon-PEEK as a bearing surface candidate for cervical total disc replacement," The Spine Journal, vol. 12, no. 7, pp. 603-611, Jul. 2012, doi: 10.1016/j.spinee.2012.07.009.
[31] Z. M. Jin, “Analysis of mixed lubrication mechanism in metal-on-metal hip joint replacements," Proceedings of the Institution of Mechanical Engineers, Part H: Journal of Engineering in Medicine, vol. 216, no. 1, pp. 85-89, Jan. 2002, doi: 10.1243/0954411021536225.

[32] S. M. Kurtz, The UHMWPE Handbook: Ultra-High Molecular Weight Polyethylene in Total Joint Replacement, 1st Edition. California, USA: Academic Press, 2004.

[33] ASTM F75-98, "Specification for Cobalt-28 Chromium-6 Molybdenum Alloy Castings and Casting Alloy for Surgical Implants (UNS R30075)," ASTM F75-98, 2001. doi: 10.1520/F0075-98.

[34] A. Wang and A. Essner, "Three-body wear of UHMWPE acetabular cups by PMMA particles against $\mathrm{CoCr}$, alumina and zirconia heads in a hip joint simulator," Wear, vol. 250, no. 1-12, pp. 212-216, Oct. 2001, doi: 10.1016/S0043-1648(01)00643-3.

[35] A. Tchako and A. M. Sadegh, "Stress Changes in Intervertebral Discs of the Cervical Spine Due to Partial Discectomies and Fusion," Journal of Biomechanical Engineering, vol. 131, no. 5, May 2009, doi: 10.1115/ 1.3118763 , Art. no. 051013 .

[36] U.-K. Chang, D. H. Kim, M. C. Lee, R. Willenberg, S.-H. Kim, and J. Lim, "Changes in adjacent-level disc pressure and facet joint force after cervical arthroplasty compared with cervical discectomy and fusion," Journal of Neurosurgery: Spine, vol. 7, no. 1, pp. 33-39, Jul. 2007, doi: 10.3171/SPI-07/07/033.

[37] S. Shankar, L. Prakash, and M. Kalayarasan, "Finite element analysis of different contact bearing couples for human hip prosthesis," International Journal of Biomedical Engineering and Technology, vol. 11, no. 1, pp. 66-80, Jan. 2013, doi: 10.1504/IJBET.2013.053712.

[38] F. A. Alnaimat, D. E. T. Shepherd, and K. D. Dearn, "The effect of synthetic polymer lubricants on the friction between common arthroplasty bearing biomaterials for encapsulated spinal implants," Tribology International, vol. 98, pp. 20-25, Jun. 2016, doi: 10.1016/ j.triboint.2016.02.014.

[39] Z. M. Jin, D. Dowson, and J. Fisher, "A parametric analysis of the contact stress in ultra-high molecular weight polyethylene acetabular cups," Medical Engineering \& Physics, vol. 16, no. 5, pp. 398-405, Sep. 1994, doi: 10.1016/1350-4533(90)90006-T.

[40] A. L. Galvin et al., "Effect of conformity and contact stress on wear in fixed-bearing total knee prostheses," Journal of Biomechanics, vol. 42, no. 12, pp. 1898-1902, Aug. 2009, doi: 10.1016/j.jbiomech.2009. 05.010 .

[41] I. J. Udofia and Z. M. Jin, "Elastohydrodynamic lubrication analysis of metal-on-metal hip-resurfacing prostheses," Journal of Biomechanics, vol. 36, no. 4, pp. 537-544, Apr. 2003, doi: 10.1016/S0021-9290 (02)00422-0. 